Two measures are needed to describe numerically the activity of the intornodal cambium in terms of annual incroment. These are 'specific wood volume increment', a measure of additive growth, and 'specific increment of cambial area', a measure of multiplicative growth. The mean area of the internodal cambium is the basis of reference for both, since it is the measure of that which is active in growth. The former measure of specific growth is numerically equal to ring width, and the manner of its factorial control has already been considered. Data for the latter are new. The geometry of the apical meristem and its products is too complex for the ready computation of specific terminal growth, but it can be shown empirically that internode length is a valid measure of apical activity. Analysis of internodal wood volume growth into its three linear components leads to the conclusion that the determinants in control of wood growth act mainly through their effect upon apical activity and upon specific increment of cambial area.

\section{Industrial High-Speed Photography}

There have been three international congrosses on high-speed photography, held respectively in Washington (1952), in Paris (1954) and in London (1956) (Nature, 178, 1440; 1956). It was felt that much might be gained if tho many recent developments in techniques could be made more widely known in industry, and if the problems of industry could be brought to the attention of those working in this specialized field of applied physics. As a first step, a conference was organized by the Scientific and Tochnical Group of the Royal Photographic Society in collaboration with the Department of Scientific and Industrial Research, and was held at the Royal College of Science and Technology, Glasgow, on June 21. It is indicative of the present wide interest in the subject that more than one hundred people attended the conference, representing many industrial firms, Government and Service departments, and universities. After the opening address by Sir David Anderson, there followed $\theta$ ight technical papers. The papers presented at the conference and a résumé of the discussion have recently been published ( $J$. Photog. Sci., 5, No. 5; 1957), providing a most valuable survey of industrial applications of high-speed photography. The conference as a whole was an outstanding success, and the organizers are to be congratulated on their work. It is most encouraging that such wide interest has been shown by industries in all parts of the country in the application of new physical techniques to their problems.

\section{Trevelyan Scholarships}

Afrer consultation between a number of industrial companies and representatives of the Universities of Oxford and Cambridge and of schools, the companies concerned are to provide financial support for scholarships of a new kind to enable selected boys to attend theso universities. Dr. G. M. Trevelyan has agreed that the awards should bear his name. The Trevelyan Scholarships will be open to boys of British nationality, educated at schools in the United Kingdom, who have secured admission to one of the colleges at Oxford or Cambridge. Their value will be $£ 450$ per annum for three years, extonded to four years in exceptional circumstancos, and will not depend on parents' income. Financial support from industrial companies is available to ensure that twelve to fourteen scholarships can be awarded annually at each university for the initial five-year period of the scheme.

The sponsors hope that these scholarships will encourage boys to pursue a broader range of studies in the sixth form without impairing their chances of going to a university through lack of financial support. The selectors will therefore look for evidence that a candidate can both profit fully from an honours course and show that he has undertaken some exact. ing task or projoct. This might be a purely intellectual inquiry or one involving personal observation and travel. A written account of this must be submitted, together with a report on the boy from his headmaster. The first selections will be made in November 1958 by a committee consisting of representatives of the Universities of Oxford and Cambridge and of industry in equal numbers under a permanent chairman. A steering committe has been established, the members of which represent industry, schools and the universities concerned. The chairman is Sir Walter Benton Jones, and Mr. R. Peddie, of 17 Westbourne Road, Sheffield 10 (to whom inquiries may be addrossed), is secretary.

\section{Field Studies Council}

The Field Studies Council has completed its arrangements for 1958. Programmes are available of the courses at each of the Field Centres: Preston Mountford, near Shrowsbury; Malham Tarn, near Settle, Yorkshire ; Juniper Hall, Dorking; Flatford Mill, near Colchester; Dale Fort, Haverfordwest; and the Skokholm Bird Observatory, Haverfordwest. The Council has a small bursary fund which is available to reduce the fees charged in individual cases of merit. Additional funds are also available through the Carnegie United Kingdom Trust to assist local natural history and scientific societies. Further information can be obtained from the Publicity Secretary, Field Studies Council, Ravensmead, Keston, Kent.

\section{Announcements}

DR. K. L. Sutherland, an assistant chief of the Commonwealth Scientific and Industrial Research Organization Division of Industrial Chemistry and leader of its Physical Chemistry Section, has been awarded the H. G. Smith Memorial Medal. The Medal is awarded each year by the Royal Australian Chemical Institute to the member who, in the opinion of the Council of the Institute, has contributed most to the development of some branch of chemical science.

A SERIES of natural history lectures for junior audiences will be given by members of the staff of the British Museum (Natural History) during the Christmas holidays, starting on December 27. These lectures will be illustrated by films, lantern slides, specimens, etc., and are intended to provide something of interest for boys and girls aged 10-16 years. Further information can be obtained from the Museum Guide Lecturer, British Museum (Natural History), Cromwell Road, London, S.W.7.

AN evening reception and reunion will be held at University College, London, on February 28 from 6.30 to 9 p.m. Former undergraduates or postgraduates who entered the College during the years 1934-38 are invited. Applications for tickots (which are limited and may have to be allocated by ballot) should be made to the Assistant Secretary, University College London, Gower Street, W.C.1. 